\title{
Spatially Explicit Biomass Supply Sustainability Analysis for Bioenergy Mill Siting in Georgia, USA
}

\author{
Chris J. Cieszewski ${ }^{*}, 1$, Shangbin Liu ${ }^{2}$, Roger C. Lowe ${ }^{3}$ and Michal Zasada ${ }^{4}$ \\ ${ }^{I}$ Warnell School of Forestry and Natural Resources, University of Georgia, USA \\ ${ }^{2}$ Biostatistician, Premier Research Group Ltd., USA \\ ${ }^{3}$ Warnell School of Forestry and Natural Resources, GIS Analysis, University of Georgia, USA \\ ${ }^{4}$ Faculty of Forestry, Warsaw University of Life Sciences, Poland
}

\begin{abstract}
Forest production sustainability is a broad and controversial subject that is frequently argued but rarely computed. Especially in the context of private forest ownership the results of erroneous assessment of forest production sustainability, such as in the case of woody biomass production for local mill operations, may result in economical losses, in lower regional employment rates, and decreased prosperity and competitiveness. We describe in this article a simulation-based quantitative approach to sustainability analysis of forest biomass production and utilization in the context of new bioenergy mill siting. The analysis is based on the best available forest inventory data and on the most upto-date knowledge of natural resource growth and yield dynamics as modelled by various studies available in the literature. The data used includes the USDA Forest Service FIA forest survey data as well as an enhanced analysis of data indicating locations of Intensive Management Plantations (IMP) at a county level, since such information, while not publicly available, has a significant impact on biomass production expectations. Using these data, simulated according to the state-of-the-art knowledge of regional growth and yield characteristics, we determine sustainable harvest levels (SHLs) for the purpose of siting bioenergy mills for 10- to 20-year production cycles. The simulations are conducted for each individual county of Georgia for four radii of procurement areas. The derived county level information on sustainable levels of biomass production, which vary for different units of analysis, can be used as a reference for effective forest utilization planning and for mill siting.
\end{abstract}

Keywords: Intensive management, sustainability, harvest level, mill siting, Mapmaker, OPTIONS, forest inventory and analysis.

\section{INTRODUCTION}

Forest products are important components of industry in the southern United States, which has 86.6 million hectares of forestland, constituting about $40 \%$ of the region's land area, with the Southeast being $60 \%$ forested. Around $90 \%$ of the southern timberlands are private, and about $14 \%$ of the total southern private timberland is in pine plantations $[1,2]$. The southern region of the USA has produced more timber than any other country in recent years [3].

The current projections suggest an increasing demand for raw wood and wood products from areas decreasing in commercial forests due to fast population growth and subsequent urban expansion, urban sprawl and other development uses. The rate of urbanization is such that even the nation's largest tree planting effort, the Conservation Reserve Program (CRP), could not offset acreages of forests converted during the same period. Most of the projected net reduction is in the Southeast region, especially around fastgrowing areas such as Atlanta, GA-USA [2-8].

Address correspondence to this author at the University of Georgia, USA; Tel: 706.542.8169; Fax: 706.542.8356;

E-mails: thebiomat@gmail.com,c@cjci.net
Establishment of a new mill or other industrial facility is a complex process, requiring information about availability of raw material for its production for a given period of time necessary for the amortization of the associated costs. The area of the commercial forests within operational distance from any given facility location, called a procurement area, determines the biomass production capabilities of the natural resource located within this area. The maximum biological productivity in terms of the biomass volume production per year that can be sustained over a long period of time, while harvested within this area, is denoted here as the sustainable harvest level (SHL), which we consider for the purpose of assessing potential mill siting. The SHL is considered only within prescribed forest management practices, excluding premature harvesting, high grading, deforestation, or other mal-practices inconsistent with the Forest Best Management Practices (BMP) as defined by the GFC in 1999 [9]. Furthermore, the SHL refers to the natural resource's biological capability of biomass production and assumes the landowner's commitment to maintaining commercial forest production and willingness to sell the produced woody biomass on a free market. In reality, the SHL should be corrected for the fact that not all landowners want to maintain forests and not all of those who maintain are willing to harvest their forests or sell the woody biomass. 
The study presented here describe the first step in this direction and further follow up study are recommended.

Past research has demonstrated that current pine productivity in the US South can be doubled or even quadrupled through application of intensive pine plantation management practices $[10,11]$. The most important factors in intensive pine plantation management practices are extensive site preparation, herbicide control against juvenile growth competition, and plantation fertilization. Other silvicultural treatments may further increase effective growth utilization through thinning and wood quality by pruning, which may be used in stands managed for solid wood products.

In the face of urban expansion and environmental pressure to reduce the numbers of acres dedicated to plantation forestry, the dramatic increase in production of intensively managed plantations may well be the solution allowing us to maintain sufficient forest biomass supplies to meet the growing demand of modern societies. Indeed, some projections have indicated that intensive pine plantation management could lead to sustainable or even increased future wood production despite a decline in the forestland base [12-14].

Forest management in the Southern US has been intensifying over the past two decades, setting a trend that is expected to continue [15]. The forest industry and Timber Management Organizations (TIMOs) in the southeast United States have been adopting intensive pine plantation practices, increasing growth rates and investment returns compared to traditional management, which consists only of site preparation and planting. Non-industrial private forest (NIPF) landowners traditionally have not been applying intensive pine plantation practices, but may do so in the future if the prices of wood increase by selecting costeffective treatments to achieve increased production [16-18]. The South is expected to increase the production of forest products in the future and to become the main source of forest products, including an increasing share of its production from the fast-growing intensively managed pine plantations [19, 20].

Georgia, located in the southeast portion of the region, has the most commercial timberland in the country and ranks third in the rate of average annual development. Georgia is particularly affected by urbanization, with a projected reduction in the forestland base in the future. The landowners in Georgia benefit from relatively strong demand and attractive prices for pine and hardwood stumpage. This is a result of a concentration of forest industry processing and manufacturing facilities in the state. With 13 pulp/paper mills, Georgia produces more pulp/paper than any other state in the nation. Moreover, in addition to the existing 144 sawmills, 12 plywood/veneer plants, 20 postpole producers, 5 composite plants, and 12 other types of plants located in Georgia [21], with the emerging carbon credits and carbon trading in recent years, Georgia has become one of the main targets for building new bioenergy and bio-fuel mills intended to produce energy and fuels from woody biomass so abundant in this forest-rich state.

Much consideration is currently given to bioenergy and bio-fuel production from just the harvest residue and un- merchantable thinning biomass that have traditionally been extremely inexpensive, but with time it may become evident that there may be not enough biomass waste to feed all the new plants. Thus, the plants may eventually be forced to use other, more expensive parts of the forest biomass, which might have negative impact on the plant cost effectiveness. Accordingly, there is a need for estimating the levels of forest biomass that can be produced at different locations in Georgia given the existing forest inventories and their biological capabilities that vary throughout the state.

The area of IMPs in Georgia, as well as other eastern states, cannot be known accurately, because corporate information about management specifics in the forest products industry is kept confidential and the forest management practices applied by a large amount of NIPF landowners are inconsistent and uncertain. Based on the estimates of former research and surveys [16, 17, 22, 23] and knowledge of Georgia's specific conditions, [24] identified that the actual number of intensively managed pine plantation areas is most likely at least $30 \%$ of all plantation acreage in the state of Georgia. To date estimates of IMP areas, or the proportion of plantation acres managed as IMP, have been available only at regional- or statewide scales. We estimated the IMP areas at the higher resolution of the county level [25]. On the basis of the higher resolution IMP area estimations, the SHLs for each county within four different radii of procurement areas were determined, and can be used as hypothetical references for mill siting.

\section{DATA}

The data used in this analysis come from the most recent USDA Forest Service FIA Unit permanent sample plot (PSP) data for Georgia and its five adjacent states, and have been downloaded from the FIA DataMart database (http://fia.fs.fed.us/tools-data/). The USDA Forest Service FIA Unit collects the data under the new annual forest inventory cycles (one cycle per year per state), which began in 1998 after the transition from the former periodic inventory system (where each state was measured once every 10 to 20 years) to the current annual forest inventory system. Under the current system FIA conducts forest surveys in each state annually in cycles measuring $20 \%$ of state PSPs per year. Thus it takes five cycles to measure all $100 \%$ of each state's PSPs, four cycles to measure $80 \%$ of the PSPs, etc. Since the data need to be cleaned, verified, and checked for quality purposes, it takes more than a year to make the surveying data from each cycle available to the public. At the time of this analysis the following data were available and used in this study: Georgia 2003 cycle 4, Alabama 2003 cycle 4, Florida 1995 cycle 2, North Carolina 2002 cycle 3, South Carolina 2001 cycle 3, and Tennessee 2003 cycle 4. The FIA data were strengthened with other data, available publicly and privately, as described in [26-28].

The sampling design of the FIA plots is a combination of systematic and random sampling [29]. About 100 features are recorded for each plot, subplot and condition, including ownership, forest type, stand age, stand origin, site productivity class, site index and site index base age, land use class, basal area per area unit, treatment opportunity class, expansion factors for area, volume, growth, mortality and removals. Over 60 variables are recorded at the tree 
level. These include species and species groups, current and previous dbh, total height, quality class, crown ratio and crown class, damage and its reason. FIA inventories are commonly designed to meet the specified sampling errors at the state level at the $67 \%$ confidence level (one standard error). The mandated sampling error cannot exceed 3\% error per 405 thousand hectares of timberland. The target sampling error for volume of growing stock on timberland is 5\% (Eastern U.S.) error per 28 million $\mathrm{m}^{3}$ (FSH 4809.11).

\section{METHODS}

Since the FIA plot data was surveyed at different years for the six involved states, to avoid the misuse of stand age, a new variable called "year of establishment" (yoe) was used. It represents the year when a given stand was established. By doing this, datasets of six states were set at the same timemeasurement level. A county list was generated in Arcview for each centered county within a circle having a radius of $40,80,120$, and $160 \mathrm{~km}$. On the basis of the county map, datasets were created for simulations for each centered county with the four different radii; four procurement areas were created for each of the 159 Georgia counties. Each procurement area was defined by a circle, with the center being in the centroid of the procurement area's central county, and by the circle's radius of $40,80,120$ or 160 kilometers. All and only counties with centroids within the given radius were included in the procurement area regardless of what proportion of the county was inside the circle defined by the procurement area radius. Since the largest procurement area radius considered in this study was $160 \mathrm{~km}$, this means that the woody biomass would be transported from up to $160 \mathrm{~km}$ linear distance (possibly greater road distance) within a total procurement area of up to approximately 8 million ha. The smallest considered radius was $40 \mathrm{~km}$, which implies up to $40 \mathrm{~km}$ of linear distance for transportation and only up to about 0.5 million ha of the total procurement area. However, in some exceptional locations (e.g., on the coast) the procurement areas could be substantially smaller due to the fact that the circle defined by the given radii would not be completely realized.

Based on a methodology framework for analysis of various management practices and regulatory constraints and their impacts on resource and harvesting sustainability [13, 14,27 investigated the impact of the rotation age, intensive management practices, and harvesting limits on wood production, harvesting opportunities, and long-term resource sustainability via long-term simulation analysis in a spatially explicit estate management simulation software called OPTIONS.

The main features of OPTIONS include:

- $\quad$ spatially explicit forest estate modeling capability;

- $\quad$ forecast for individual polygons;

- $\quad$ annual processing of data;

- $\quad$ capability for large database processing;

- $\quad$ GIS functionality (topology for polygons from up to 25 optional GIS layers);

- $\quad$ user defined "confidence" tolerances;
- $\quad$ connectivity with external GIS systems through links to particular basic polygons,

- combinations of constraints and targets for individual spatial layers.

The complexity of OPTIONS allowed populating the model with inventory data overlaid with spatially explicit locations of towns, cities, roads, streams, rivers and other features. Subsequent study required adapting appropriate yield tables to know and plan silvicultural treatments, management regimes and their allocation for GA forests. The OPTIONS minimum data requirements are:
- polygon area,
- $\quad$ species group,
- $\quad$ site index,
- $\quad$ age (or year of establishment).

The temporal changes are based on data filled from yield tables and growth and yield models. It is also possible (desired) to add additional information from forest inventory, as:
- GIS data,
- $\quad$ silvicultural treatment characteristicss
- management regimes,
- regime allocation tables,
- $\quad$ possible management scenarios.

In this study, values of the simulation parameters used in OPTIONS were compiled from published and unpublished literature and from interviews with experts in the area of forest management in the southeastern US. Based on the ages and species group, one of the appropriate yield tables were used to define expected growth of each stand type. The considered yield tables and models included: [30-52].

In this study, five site index classes were defined with six broad species groups: natural softwoods (NSOF), traditionally managed pine plantations (PSOF), oak-pine stands (OAKP), upland hardwoods (UHWD), bottomland hardwoods (BHWD), and intensively managed pine plantations (IMP). The estimated IMP areas at the higher resolution of the county level were used. Appropriate yield tables and maturity criteria (the rotation ages) were assigned for each site/species group combination. Separate management regimes and the management regimes after harvesting were also defined for each of the six species groups. IMPs were assumed maintaining the current status in all plantations through year 2020. Finally, the harvesting priority by cut type and species groups was defined. The detailed definition and model inputs were described in [13, 14] and [27]. Based on the ages, heights, and corresponding site index values in the FIA database, five site index classes (base age 50) were assigned to different stands:

- $\quad$ very low - VLOW (up to 50 feet at the base age of 50),

- $\quad$ low - LOW (56-65 feet),

- $\quad$ medium - MED (66-75 feet),

- $\quad$ high - HIGH (76-85 feet),

- $\quad$ very high - VHIG (above 85 feet). 
For each class and species group, yield tables with the values for the site indices of 50,60,70, 80 and 90 feet accordingly were assigned with data for ages up to 60 years.

Forest maturity criteria were based on arbitrary age by species group and site index class. Detailed data come from analysis of the study by [16] and other sources including personal communications with experts.

Simulations were iteratively run to obtain the SHLs by the year 2020 for each centered county with the four different radii.

\section{RESULTS}

\subsection{SHL identification}

As expected, the outcome of the simulations suggested that the SHL would increase proportionally to the area defined by the radius increasing from each centered county of Georgia (Fig. 1). With a $160-\mathrm{km}$ radius the SHL ranged from 30.5 million $\mathrm{m}^{3}$ per year for Camden county up to 61.1 million $\mathrm{m}^{3}$ per year for Spalding county. The SHL varied from 17.8 to 36.8 million $\mathrm{m}^{3}$ per year for centered counties with $120-\mathrm{km}$ radii, 10.3 to 19.9 million $\mathrm{m}^{3}$ per year for centered counties with $80-\mathrm{km}$ radii, and 2.6 to 8.2 million $\mathrm{m}^{3}$ per year for centered counties with 40-km radii (Table 1).

The distribution of the SHL showed different patterns for centered counties depending on the length of the the radius. Within a small area, say a $40-\mathrm{km}$ radius, the high SHL regions were mainly concentrated in southeast Georgia, especially for the border region of South Carolina. The regions along borders of Florida and Alabama also showed relatively high SHLs. In general, the southeastern part of Georgia provides more fiber resources than other regions in Georgia. For each centered county in the region of the Atlantic coastal plain, within a small radius, the proportion of the area falling onto the Atlantic Ocean is only a small part in all acreage of the whole buffered regions. This leads to the conclusion that the Atlantic coastal plain region has a moderately high SHL (Fig. 2d). With an increasing radius, the proportion of Atlantic Ocean took a larger proportion in all acreage of whole buffered regions for a given centered county. It caused the region of the Atlantic coastal plain to have a very low SHL. The larger the radius was, the more acreage with a low SHL (Fig. 2a-c). The regions alongside boundaries of South Carolina, especially the regions around South Augusta, had very high SHLs regardless of the radius with respect to a centered county (Fig. 2).

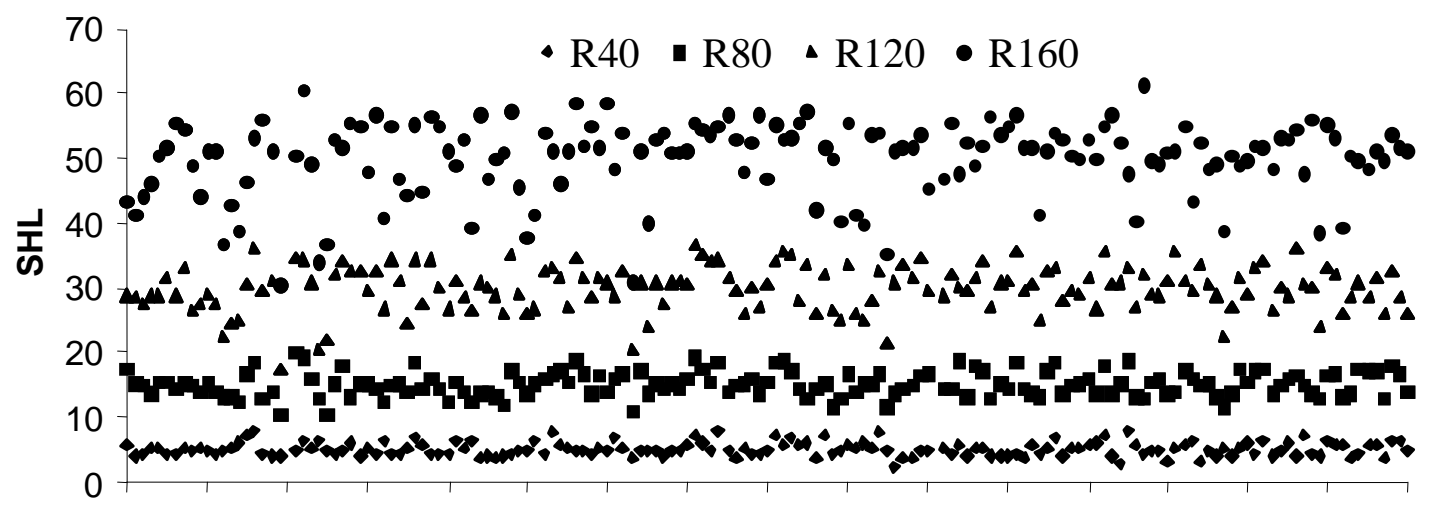

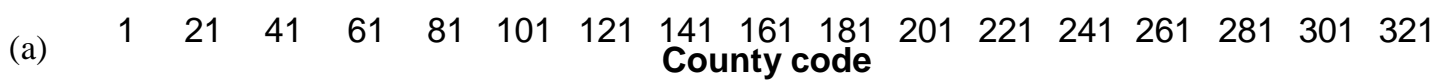

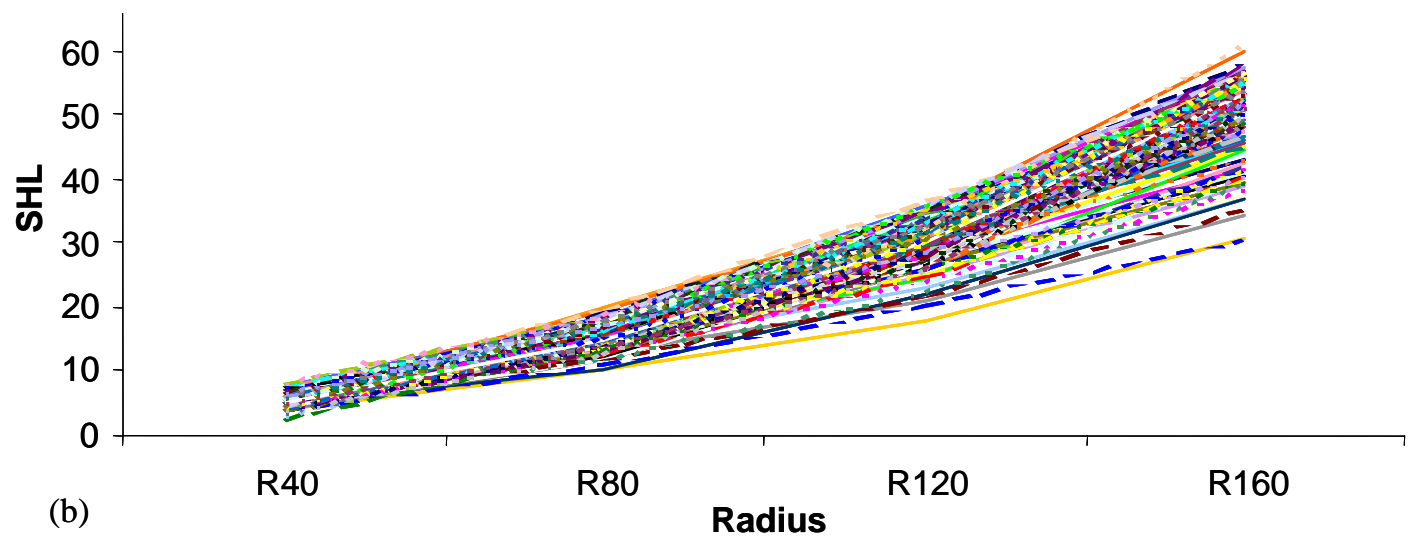

Fig. (1). The SHLs (million $\mathrm{m}^{3}$ per year) for each centered county of Georgia with 160, 120, 80, and $40 \mathrm{~km}$ radii. Classified by (a) radius; (b) county. 
Table 1. SHLs (Million $\mathbf{m}^{3}$ Per Year) for Each Centered County with 4 Different Radii (km)

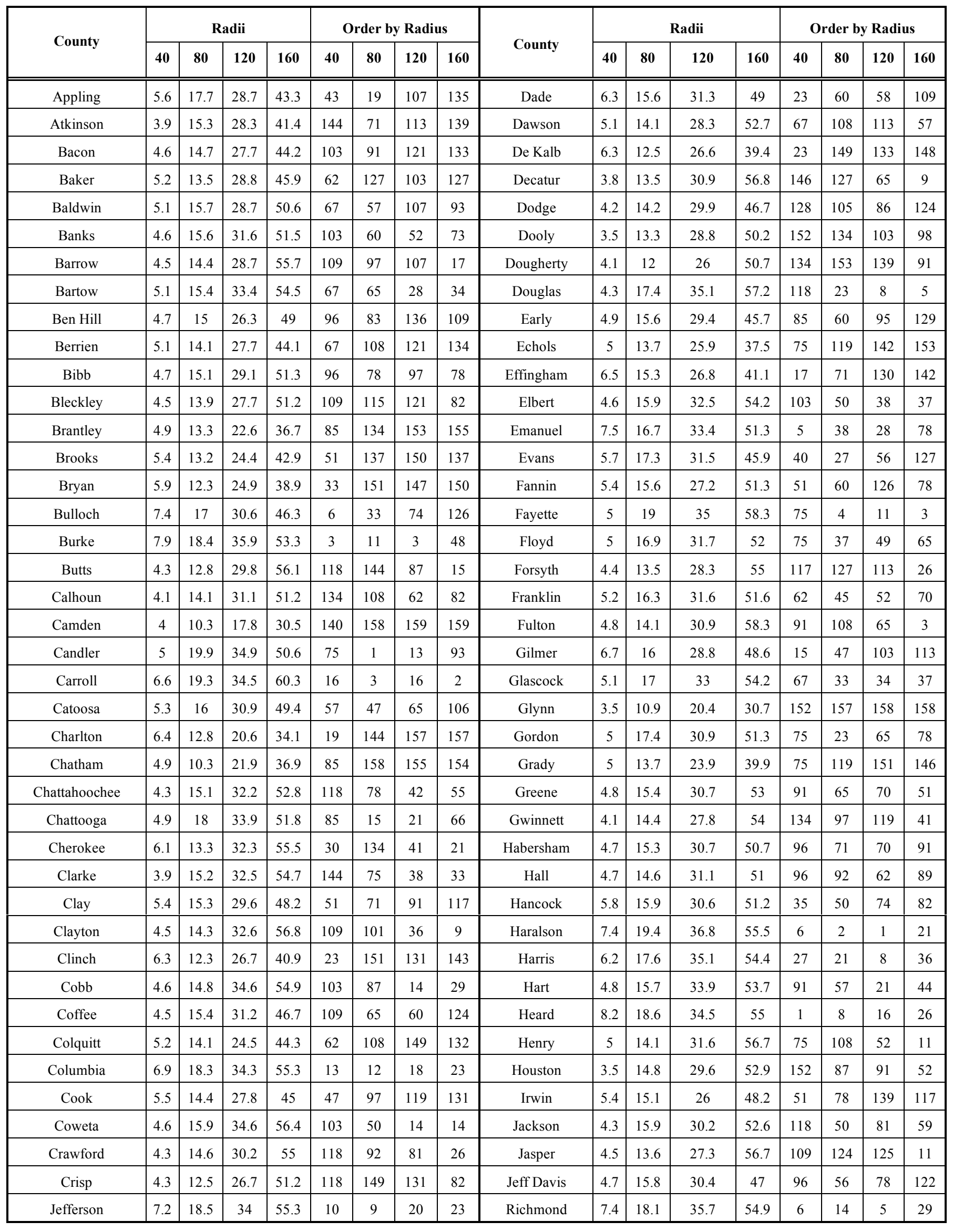


(Table 1) contd...

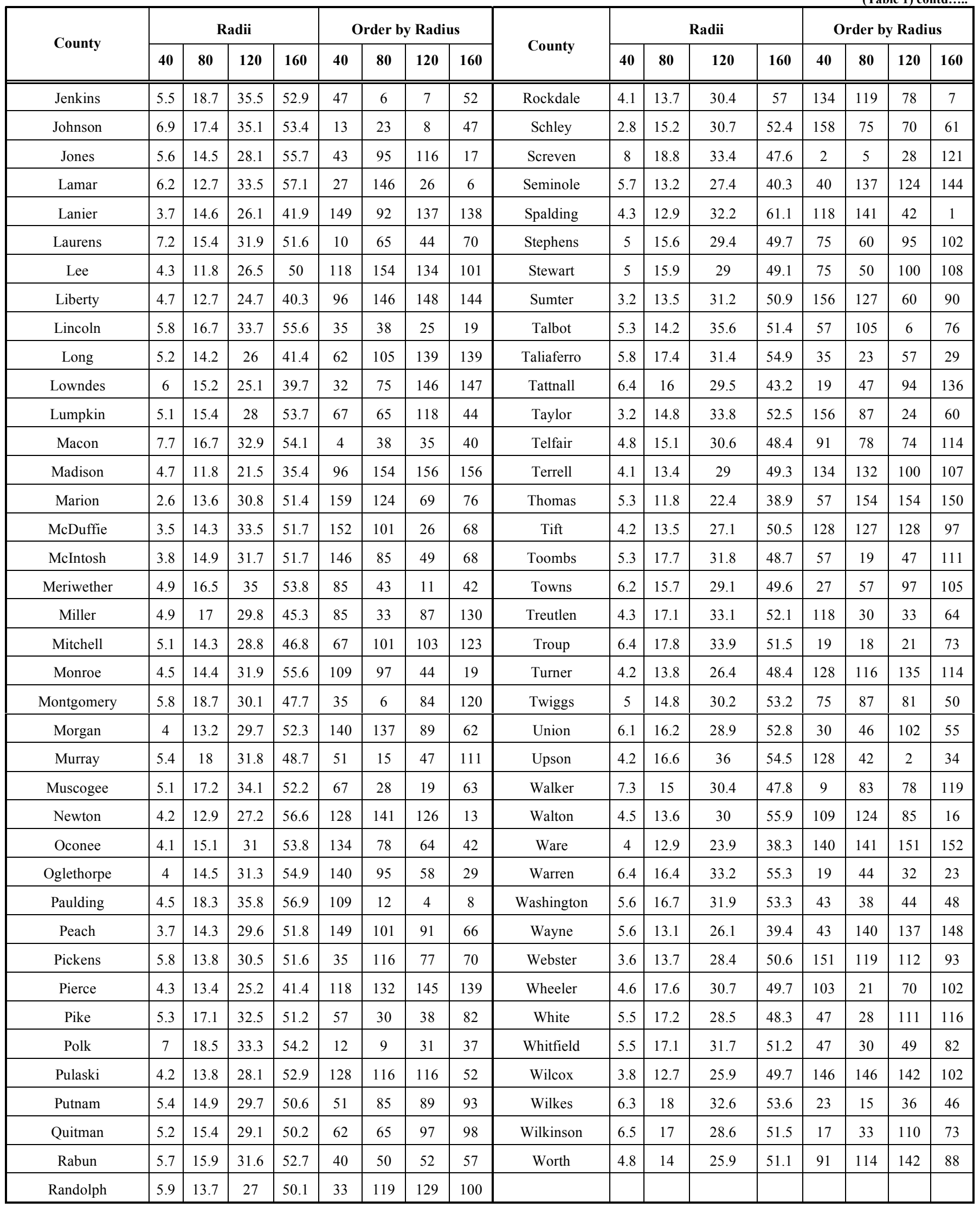



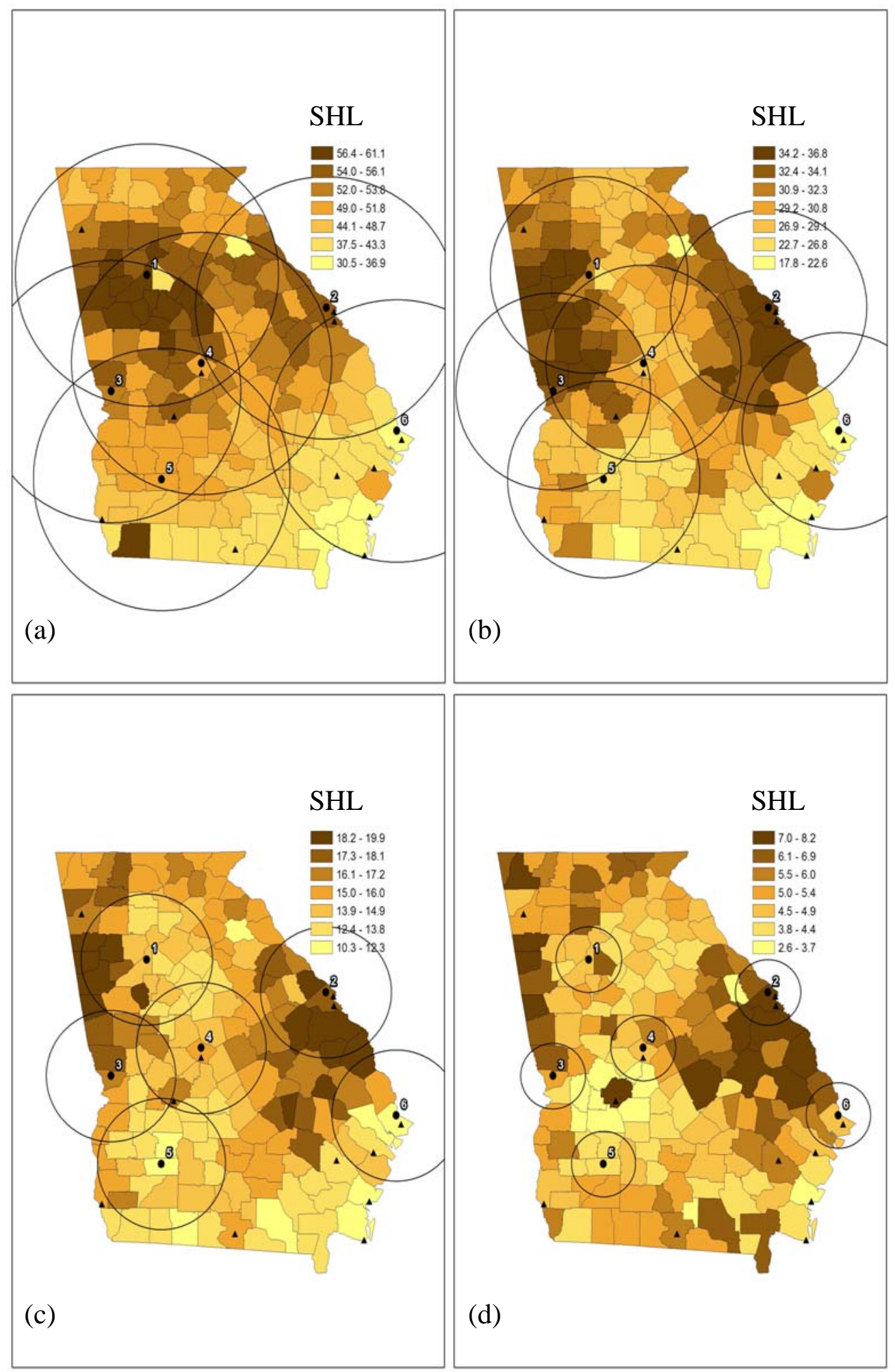

Fig. (2). The distribution of the SHLs (million $\mathrm{m}^{3}$ per year) for each centered county of Georgia, with (a) 160-, (b) 120-, (c) 80-, and (d) 40$\mathrm{km}$ radius (as circles in graphs show). The triangles mark the location of pulp mills. The dark circles represent the location of the major cities. 1 - Atlanta, 2 - South Augusta, 3 - Columbus, 4 - Macon, 5 - Albany, and 6 - Savannah.

On the other hand, with large radii, such as $120-\mathrm{km}$ or more, the high-SHL regions were mainly concentrated around the four major cities of Atlanta, Columbus, Macon, and South Augusta (Fig. 2a, b). Within a large radius of these centered regions, a high SHL would be maintained by year 2020. The main contributors to a high SHL for these centered regions were forest resources in Alabama and South Carolina close to Georgia and the southeast of Georgia. This does not imply that the regions surrounding the major cities 
of Atlanta, Columbus, and Macon had a high SHL and a large amount of forest inventory.

\subsection{Mill Siting}

By considering the condition of transportation and existence of mills, Macon would be a good choice for siting a mill under the restrictions of harvested volumes mainly coming from Georgia itself. Without this restriction, South Augusta would be a good location to place a mill. The volumes available for harvest were unevenly distributed in the counties surrounding Macon with a $160-\mathrm{km}$ radius (the region of Macon with a $160-\mathrm{km}$ radius is the same as that of Bibb county with a $160-\mathrm{km}$ radius). This radius covers 109 counties of which 104 are in Georgia and the remaining 5 (Barbour, Chambers, Lee, Randolph, and Russell) are in Alabama. Throughout the simulation the harvestable volumes (i.e. volumes available for harvesting) showed a declining trend (Fig. 3a). The harvestable and harvested volumes are mainly located in Georgia except for a few years (e.g. 2015 and 2016) in which they are evenly distributed in Georgia and Alabama (Fig. 3).

At the beginning of the simulation (year 2000), the counties located to the southeast and north of Macon have the highest harvestable volumes in the procurement areas surrounding them. The top 10 counties (Jefferson, Washington, Worth, Oglethorpe, Walton, Fulton, Emanuel, Burke, Hall, and Wilkes) contributed to about 1/4 of the harvestable volume in the 104 counties of Georgia (Fig. 4a).
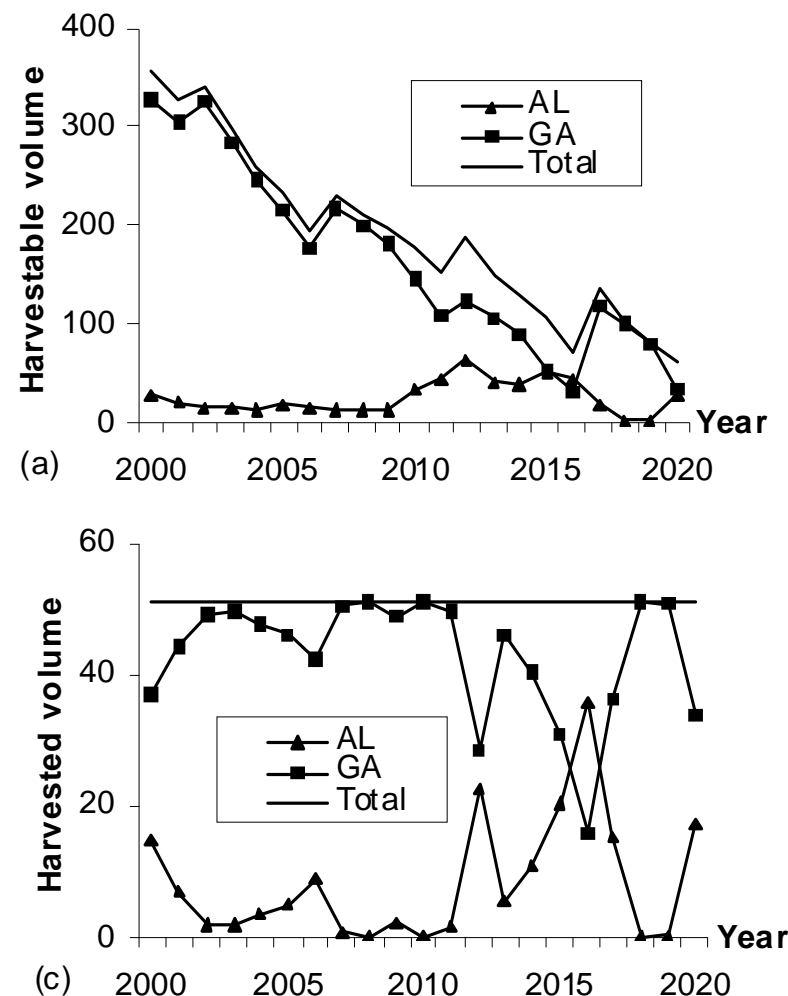

By 2010 the share of the top 10 counties (Laurens, Burke, Emanuel, Appling, Wheeler, Hancock, Coffee, Mitchell, Wilcox, Talbot) would make up about $1 / 3$ of the total harvestable volume (Fig. 4c). After 2015 all counties within a $160-\mathrm{km}$ radius of Macon would have a low level (less than 1 million $\mathrm{m}^{3}$ per year for each county) of harvestable volumes (Fig. 4d, e). On the other hand, at the beginning of the simulation the major part $(64 \%)$ of harvestable volumes came from the hardwoods (Fig. 4k), which include UHWD, BHWD, and one half of the OAKP. By 2010 the major part $(95 \%)$ of harvestable volumes would move to the softwoods (Fig. 4h), which include IMP, PSOF, NSOF, and one half of the OAKP. By 2020 the harvestable volumes from hardwoods $(56 \%)$ would exceed those from softwoods (44\%) again (Fig. 4j, o).

The distribution of the harvested volumes by counties in the Macon procurement area of a $160-\mathrm{km}$ radius showed that in aggregate during the first decade the harvested volumes would mainly come from the counties located at the southeast or north of Macon (Fig. 5a-c). The harvested softwoods would mainly come from the counties southeast of Macon, e.g. the top 10 counties (Emanuel, Laurens, Mitchell, Burke, Oglethorpe, Bulloch, Johnson, Coffee, Jefferson, and Dodge) would produce more than $1 / 2$ of the total harvests in 2010 (Fig. 5h). The counties north of Macon supplied most of the hardwood demand, e.g. the top 10 counties (Oglethorpe, Jasper, Paulding, Walton, Monroe, Jackson, Newton, Douglas, Forsyth, and Troup) would make up about $1 / 2$ of the total harvest at 2005 (Fig. 5l). After 2015
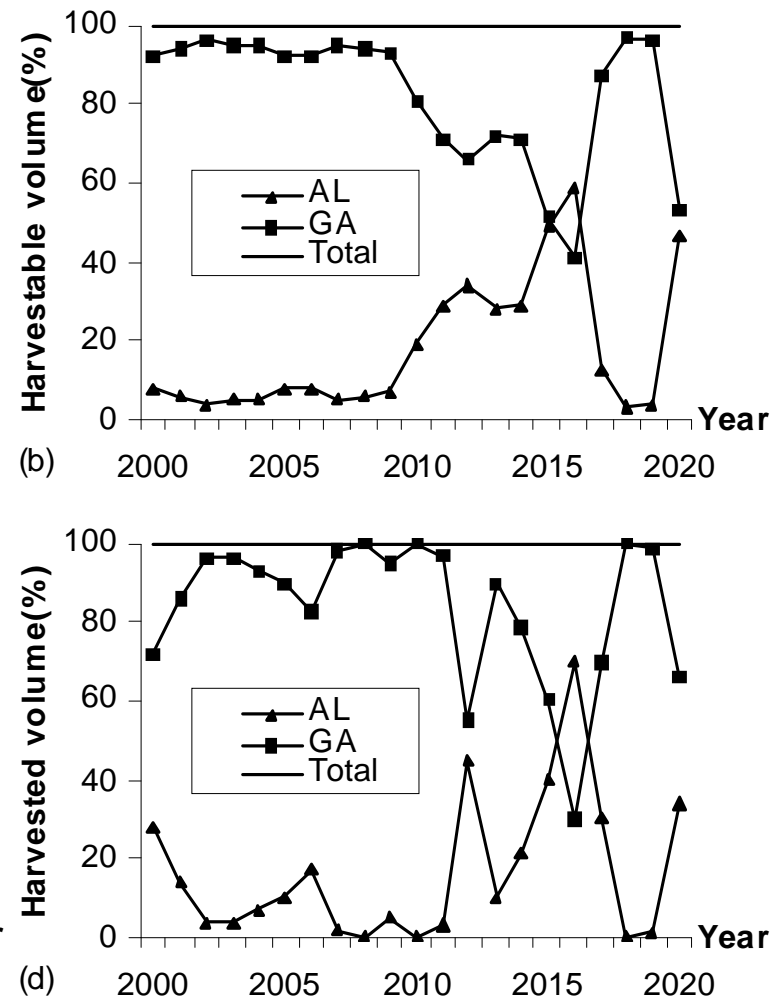

Fig. (3). The harvestable and harvested volumes by states over years for Macon with a 160-km radius. (a) the absolute harvestable volume (million $\mathrm{m}^{3}$ per year); (b) the percentage harvestable volume; (c) the absolute harvested volume (million $\mathrm{m}^{3}$ per year); and (d) the percentage harvested volume. 

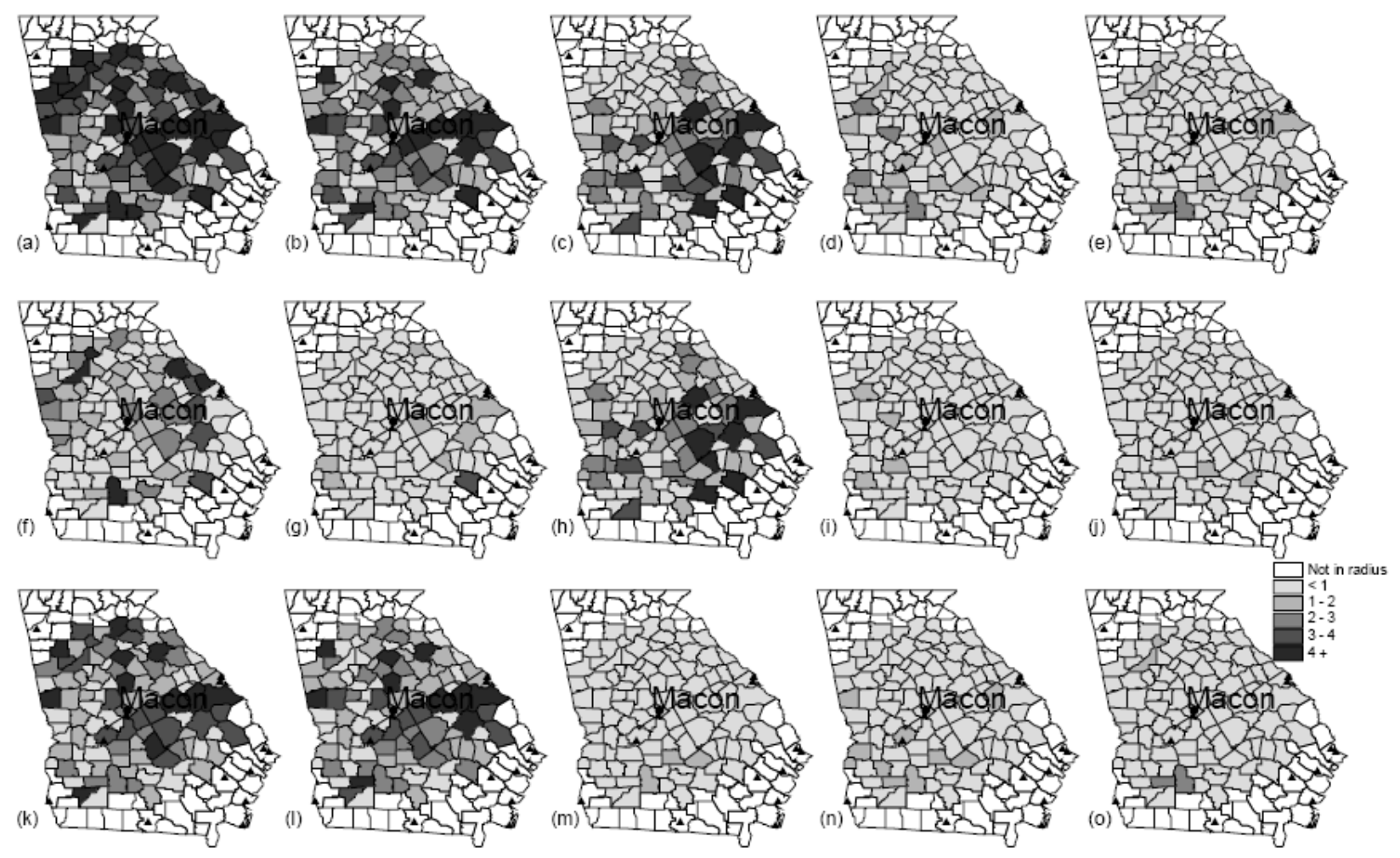

Fig. (4). The distribution of the volumes available for harvest (million $\mathrm{m}^{3}$ per year) by counties for Macon with a 160-km radius. (a-e): Total; (f-j): Softwoods; and (k-o): Hardwoods at year 2000, 2005, 2010, 2015, and 2020, respectively. The triangles mark the location of pulp mills.

in general the harvested volumes would be evenly distributed (with a slight variation for a few counties) in counties within a $160-\mathrm{km}$ radius of Macon (Fig. 5d, e). The harvests from softwoods and hardwoods would be close to each other by 2020 (Fig. 5j, o).

\section{DISCUSSIONS}

We describe in this article a simulation-based quantitative approach to sustainability analysis of commercial forest biomass use in the context of siting new bioenergy plants - using non-traditional biomass from harvest residues and pre-commercial thinnings - in addition to existing traditional pulp and timber processing plants. The presented approach is based on the best available forest inventory data and on the most up-to-date knowledge of natural resource growth and yield dynamics as modeled by various studies available in the literature.

\subsection{Bias in Determining SHLs for Each Centered County with 4 Different Radii}

\subsubsection{Potential Sources of Positive Bias in the SHL Determination}

The predictions of the SHLs for each Georgia county procurement area might have some positive bias since the assumptions that the timberland base will keep constant and all land can be managed and harvested were used in simulations, while it is reasonable to expect that there might be some decline and constraints on some land uses and regions. The bias resulting from this source is likely small since most of the current projections show that in the near future, timberland areas will remain constant [53] or have about a $2 \%$ decline $[3,8]$ in the southeast, while this kind of decline has significant regional variation. Due to rapid population growth and subsequent urban expansion and developed uses, most of the projected net reduction is in the Southeast region, especially nearby fast-growing areas such as Atlanta [2-6, 8, 21]. For those counties around fastgrowing areas such as Atlanta, the SHLs of the corresponding small radii (40 or $80 \mathrm{~km}$ ) procurement areas would be overestimated even if their estimated SHLs are at low levels (Fig. 2c, d). With the increase of the radius from each central county, the overestimates go down.

The possible various regulatory constraints, such as mandated streamside management zones and road beautifying buffers may contribute to the reduction of the commercial land base [17]. This also suggests potential overestimates of SHL for each of the procurement areas of Georgia.

\subsubsection{Potential Sources of Negative Bias in SHL Determination}

In the future, the South will continue to be counted on for timber, and an increasing share will come from relatively fast-growing pine plantations $[19,20]$. In this study it was assumed that the proportions of IMP for all plantations would remain constant through 2020. However, with 

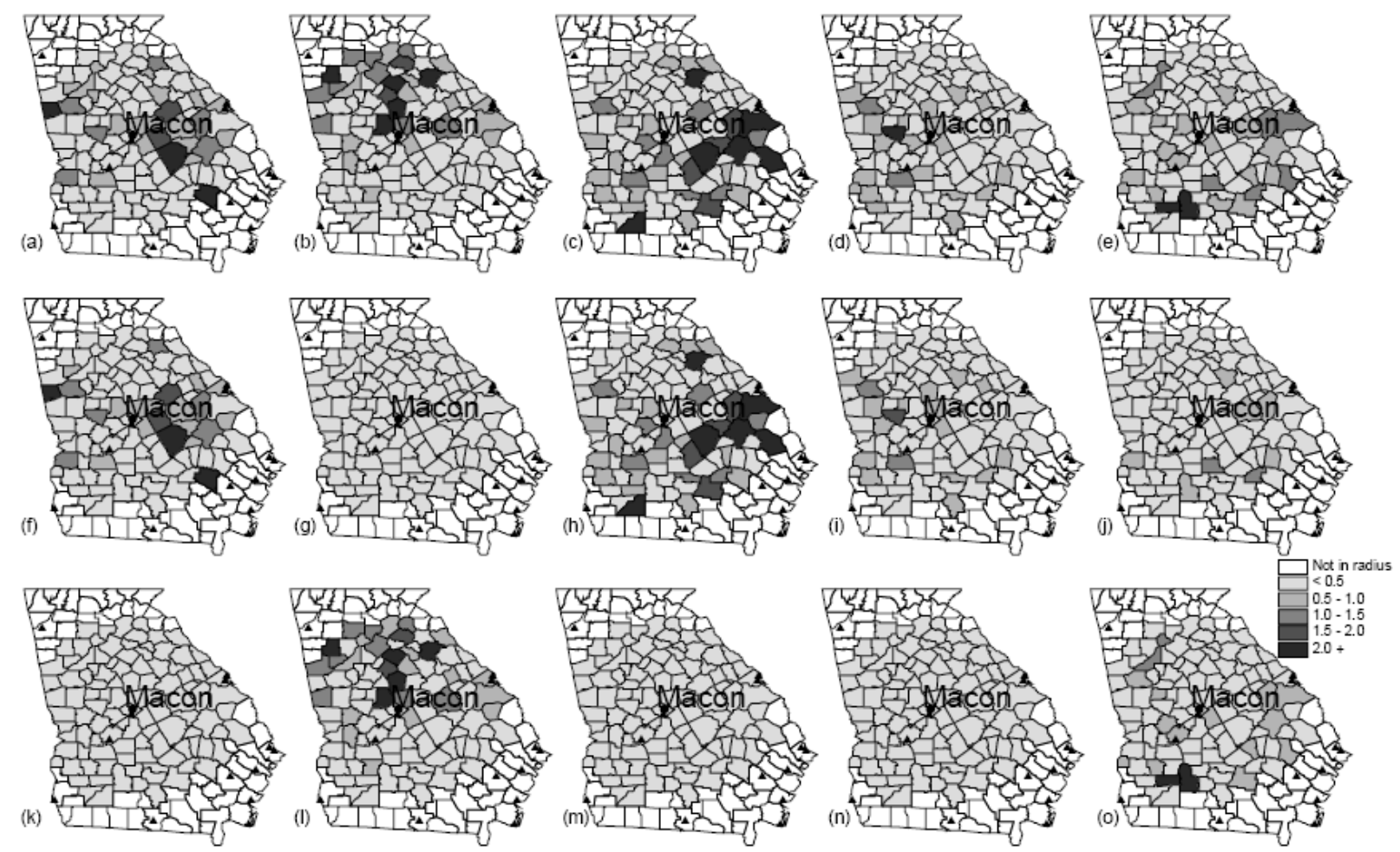

Fig. (5). The distribution of the harvested volumes (million $\mathrm{m}^{3}$ per year) by counties for Macon with a 160-km radius. (a-e): Total; (f-j): Softwoods; and (k-o): Hardwoods at year 2000, 2005, 2010, 2015, and 2020, respectively. The triangles mark the location of pulp mills.

management intensification on industrial lands, many harvested natural pine, mixed oak-pine, and hardwood stands are being artificially regenerated. The reason for considering this constant IMP proportion in simulation was for simplifying the complex prediction problem. Since even the short rotation age of the IMP in a high-site-index stand is larger than 20 years, and the goal is to find SHL by year 2020, which is less than one rotation period, for each procurement area with four different radii, the assumption of a constant IMP proportion would be reasonable. If the goal is to find SHL for a long period of time, say by year 2050, an appropriate set of transition rates to IMP should be considered in the scenarios (see $[13,14]$ for the detail).

Because the FIA data used base-age-50 site index classes that were cut off at $30.2 \mathrm{~m}$ (meter), while in reality the high productivity site indices in Georgia may exceed $40 \mathrm{~m}$, there might be a negative bias in the assessment of the production capabilities in Georgia forests by original site index in FIA data. To address this problem, timberland area and volume were generated by site productivity class, stand age class, and species groups by Mapmaker from FIA. Then the unit area of volume was calculated. Finally, the site index classes were obtained by comparing the calculated unit volume with values in the corresponding yield tables.

\subsection{Ecological, Economical and Social Aspects of Sustainability and Other Factors Not Considered in this Study}

The study presented here considered only one aspect of sustainability related to siting of new bioenergy plants in the areas, where other traditional plants might exist but, in principle, should not compete for the same biomass sources (the harvest residue and pre-commercial thinning residue for the new bioenergy and bio-fuel plants versus timber and pulp for the traditional existing plants). Furthermore, this study used an a priori assumption, that the forest stewardship and proper forest management in agreement with the BMP rules is the constraint, not a variable, and that if there is a shortage of biomass production for a plant to function the plant would not be viable for a given location. Given such assumptions, this study considered only a relatively short timeframe (long for a mill consideration) of 20 years, beyond which the conclusions of this study could be reversed.

Violating the assumptions of this study, such as maturity criteria, and for example premature harvesting of existing stands, as well as downgrading forests through improperly carried out thinning, could have negative ecological and economic impacts on long-term ecosystem changes and biomass production capabilities. Furthermore, while building new mills initially stimulates the local economy, creating new employment and improving the socio-economical conditions of the region, if the mill siting is founded on overoptimistic and therefore unsustainable harvesting levels, building of such mill could have a negative influence on the regional economy by driving wood prices higher and putting a strain on resource management and local harvesting practices.

[27] describes analysis of long-term wood production sustainability in Georgia at the state scale, while different aspects of related studies consider various ecological aspects of current forest management practices in the state including: 
analysis of green-up and adjacency constraints (e.g., [54]), assessment of the impacts of stream management zones and road beautifying buffers on forest inventory in Georgia [55, 56], and impacts of intensive management practices on the outcomes of these long-term simulations for Georgia (e.g., [24, and 13]. General sensitivity analysis of the considered simulations (e.g., [14, 57]) were also conducted.

Other factors not considered in this study include such issues as biodiversity and impact of climate change on sustainability. It would be difficult and likely less than fruitful to try to model biodiversity on such short periods of prediction time as 20 years, which is the maximum reasonable timeframe for planning a mill siting. However, for long-term sustainability analysis (e.g., [27]), where the assumption of sustainability is considered as perseverance of an ecosystem type in eternity, the biodiversity may be an important issue. [27] have applied current forest management practices synthesized by the existing literature to the simulation system with all the observed patterns of successions and transitions. They summarized their results in several unpublished reports and presentations, but did not make any specific biodiversity comparisons from the derived data.

Another issue that has not been considered is the potential climate change impact on the sustainability analysis outcomes. Possible venues that can be followed to model the climate change impact on sustainability require the development of new growth and yield models including climate variables as explanatory variables. Conducting multiple runs as sensitivity analysis would bring insight into the possible deviations dependent on the changes in such variables as the mean temperature or precipitation distribution. It needs to be noted here, that while expanding the simulations to consider sensitivity analysis for climate change is quite manageable, development of new growth and yield models with additional explanatory climate variables for all the southern US species would be a monumental task requiring huge resources in terms of both time and financing, and therefore is unlikely in the foreseeable future.

\subsection{Future Directions and Related Studies}

Intensive forest management is rapidly being adopted by the forest industry in the southeast United States in efforts to increase the normal fiber growth rates. Generally, industry is focusing on increasing fiber production on their land holdings that are close to paper and strand-board mills. Increased production on shorter rotations generates attractive returns for forest management investments done also by TIMOs. NIPF landowners looking into intensive management opportunities generally must attempt to reduce costs by selecting cost-effective treatments to achieve increased production [16-18]. Further study on this issue is to take into account the actual types of forested land ownership that cause significant differences in decisions on the future management and intensity of management.

\section{CONCLUSION}

Information derived through computer simulations of available forest inventory data can be used as a reference for deriving sustainable levels of biomass production for planning purposes and for mill placement or siting. For a $160-\mathrm{km}$ (kilometre) radius the SHLs ranged from 30.5 to 61.1 million $\mathrm{m}^{3}$ per year (million cubic meters) for various counties. The distribution of the SHLs showed different patterns for different counties and radii. Within a small radius, high SHL regions were mainly concentrated in the southeast of Georgia. Within a large radius, the high SHL regions were mainly concentrated in regions around the following four major cities: South Augusta, Macon, Columbus, and Atlanta. The region along borders of South Carolina, especially the regions around South Augusta, had very high SHLs, regardless of the radius, for all counties. According to the results of the simulations, Macon and South Augusta would be in principle the best locations for siting mills. Given that the biomass production sustainability levels at the various considered locations may be correlated with the number of existing mills, the conclusions presented here have large uncertainties associated with them since there might already be in existence a relatively large number of mills at locations with large biomass supply. Yet, given the optimistic assumptions that the bioenergy mills would run on harvest residue and pre-commercial thinning recovery biomass it would be reasonable to assume that the locations with high biomass production will imply high availability of harvest residue and pre-commercial thinning biomass for bioenergy production even in the presence of existing traditional sawmills and pulp mills utilizing the bulk of the merchantable harvested wood volume.

\section{ACKNOWLEDGEMENTS}

This study was funded in part by the Georgia Forestry Commission, the USDA Forest Service FIA Unit - Southern Research Station, the Georgia TIP3 funding, and the University of Georgia. A great many individuals contributed to this study, but we are especially grateful for the contributions of John Wells and Nathan McClure of the Georgia Forestry Commission, and Robert I. Elle, the Research Coordinator of the Fiber Supply Assessment Program at the Warnell School of Forestry and Natural Resources, UGA, who has helped much in proofreading the manuscript. We would also like to thank Dick Porterfield and Bob Warren, who were the Deans of the Warnell School of Forestry and Natural Resources at the time of this study, for their support of the Fiber Supply Assessment Program. Finally, thanks are due to the anonymous reviewers and the Guest Editor for the Open Forest Science who were very helpful in providing helpful suggestions on how to improve this article and in efficient and timely processing of the manuscript peer review.

\section{REFERENCES}

[1] Smith WD, Vissage JS, Sheffield R, Darr D. Forest resources of the United States, 1997. GTR-NC-219, USDA Forest Service, North Central Research Station, St Paul MN 2001; p. 190.

[2] Alig RJ, Butler BJ. Area changes for forest cover types in the United States, 1952 to 1997, with projections to 2050. GTR-PNW613, USDA Forest Service, Pacific Northwest Research Station, Portland, OR 2004; p. 106.

[3] Wear DN, Greis JG. Southern forest resource assessment: Summary of findings. J Forestry 2002; 100(7): 6-15.

[4] Ahn SA, Plantinga J, Alig RJ. Historical trends and projections of land use for the south-central United States. PNW-RP-530, USDA 
Forest Service, Pacific Northwest Research Station, Portland, OR 2001; p 20.

[5] Dangerfield CW, Hubbard WH. Forestry situation and outlook in the U.S. South. Research Note No. 7. Center for Forest Business, Warnell School of Forest Resources, Athens, GA 2001.

[6] Ahn SA, Plantinga J, Alig RJ. Determinants and projections of land use for the south-central United States. South. J Appl For 2002; 26(2): 78-84.

[7] Prestemon JP, Abt RC. Chapter 13 (TIMBR-1): Timber products supply and demand. In: The Southern Forest Assessment Final Technical Report, GTR-SRS-53, USDA Forest Service, Southern Research Station, Asheville, NC 2002.

[8] Alig RJ, Plantinga AJ, Ahn S, Kline JD. Land use changes involving forestry in the United States: 1952 to 1997, with projections to 2050. PNW-GTR-587, USDA Forest Service, Pacific Northwest Research Station, Portland, OR 2003; p 92.

[9] GFC. Georgia's best management practices for forestry. Georgia Forestry Commission, Macon, GA; 1999; p 71.

[10] Borders BE, Bailey RL. Loblolly pine--pushing the limits of growth. South. J Appl For 2001; 25: 69-74.

[11] Martin SW, Shiver BD. Impacts of vegetation control, genetic improvement and their interaction on loblolly pine growth in the southern United States-age 12 results. South J Appl For 2002; 26: 37-42.

[12] Pienaar LV, Rheney JW. An evaluation of the potential productivity of intensively managed pine plantations in Georgia. Georgia Consortium for Technological Competitiveness in Pulp and Paper Technology - Fiber Supply. Final Report 1996; p 33.

[13] Liu S, Cieszewski CJ. Impacts of management intensity and harvesting practices on long-term forest resource sustainability in Georgia. Math Comput Forestry Nat-Resour Sci 2009; 1(2): 52-66.

[14] Liu S, Cieszewski CJ, Lowe RC, Zasada M. Sensitivity analysis on long-term fiber supply simulations in Georgia. South J Appl For 2009; 33: 81-90.

[15] Siry JP. Chapter 14 (TIMBR-1): Intensive timber management practices. In: The Southern Forest Assessment Final Technical Report, GTR-SRS-53, USDA Forest Service, Southern Research Station, Asheville, NC 2002.

[16] Goetzl A. AF\&PA southern forest management intensity survey: Data summary and survey results. Unpublished report. Washington, DC: American Forest and Paper Association 1998.

[17] Moffat SF, Cubbage W, Cascio A, Sheffield R. Estimations of future forest management intensity on NIPF lands in the South: Results of the Southern State Foresters' Survey. Working Paper Series, SOFAC Report 14. Southern Forest Resource Assessment Consortium, Research Triangle Park, NC 1998.

[18] Moorhead DJ, Dangerfield Jr. CW, Beckwith III JR. Opportunities for intensive pine plantation management. The Entomology and Forest Resources Digital Information Work Group, College of Agricultural and Environmental Sciences and Warnell School of Forest Resources, The University of Georgia, Tifton, Georgia 31793 USA. BUGWOOD 1998; 98-002.

[19] Alig RJ, Mills JR, Butler BJ. Private timberlands: growing demands, shrinking land base. J Forestry 2002; 100 (2): 32-37.

[20] Haynes RW. An analysis of the timber situation in the United States: 1952 to 2050. PNW-GTR-560, USDA Forest Service, Pacific Northwest Research Station, Portland, OR 2003; p 254.

[21] Prestemo, JP, Butry DT, Pye JM, Stratton DT. Locations of southern wood chip mills for 2000. ; 2001 ; [Database]. http://www.rtp.srs.fs.fed. us/econ/data/mills/mills.htm [Date accessed: March 30, 2005]

[22] Cubbage FW, Siry JP, Abt RC, Wear DN, Moffat S. Forest productivity and timber supply modeling in the South. In: Proceedings of conference "Improving Forest Productivity for Timber... A Key to Sustainability" held in Duluth, MN 1998; 1-3,

[23] Thompson MT. Forest statistics for Georgia, 1997. RB-SRS-36. USDA Forest Service, Southern Research Station, Asheville, NC 1998; p 92.

[24] Zasada M, Cieszewski CJ, Borders BE. Impact of intensive management practices on long-term simulations of forest resources in Georgia. In: Proceedings of the 2002 SAF National Convention. Society of American Foresters, Winston-Salem NC USA 2002; p 64.

[25] Liu S, Cieszewski CJ, Lowe RC. Estimations on intensively managed pine plantation acreages at various scales. Georgia TIP3 Report. University of Georgia 2010.
[26] Cieszewski CJ, Iles K, Lowe RC, Zasada M. Proof of concept for an approach to a finer resolution inventory. In McRoberts RE, Reams GA, Van Deusen PC, McWilliams WH, eds. Proceedings of the Fifth Annual Forest Inventory and Analysis Symposium. November 18-20, 2003, New Orleans, LA. GTR-WO-69. U.S. Department of Agriculture, Forest Service, North Central Research Station, St Paul MN 2005; pp. 69-74.

[27] Cieszewski CJ, Zasada M, Borders BE, et al. Spatially explicit sustainability analysis of long-term fiber supply in Georgia, USA. For Ecol Manage 2004; 187(2-3): 349-59.

[28] Iles K. "Total-Balancing" an inventory: A method for unbiased inventories using highly biased non-sample data at variable scales. MCFNS [Online] 2009; 1(1): 10-13.

[29] Chojnacky DC. Double sampling for stratification: a forest inventory application in the Interior West. RMRS-RP-7, USDA Forest Service, Rocky Mountain Research Station, Ogden, UT 1998; p15.

[30] Schumacher FX, Coile TS. Growth and yields of natural stands of the southern pines. Durham, NC: T.S. Coule Inc 1960; p 115.

[31] Nelson TC, Clutter JL, Chaiken LE. Yield of Virginia Pine. Station Paper No. 124. USDA Forest Service, Southeastern Forest Experiment Station, Asheville, NC 1961; p 11.

[32] Forbes RD. Forestry handbook., New York: The Ronald Press Company; 1961.

[33] Bennett FA. Variable-density yield tables for managed stands of natural slash pine. RN-SE-141. USDA Forest Service, Southeastern Forest Experiment Station, Asheville, NC 1970; p 7.

[34] Bennett FA. Growth and yield in natural stands of slash pine and suggested management alternatives. RP-SE-211. USDA Forest Service, Southeastern Forest Experiment Station, Asheville, NC 1980. p8.

[35] Gingrich SF. Management of young and intermediate stands of upland hardwoods. RP-NE-195. USDA Forest Service, North Forest Experi Stat 1971; p26.

[36] Beck DE, Della-Bianca L. Growth and yield of thinned yellow poplar. RP-SE-101. USDA Forest Service, Southeastern Forest Experiment Station, Asheville, NC 1972; p20.

[37] Burkhart HE, Parker RC. Site and yield information applicable to Virginia's hardwoods: a review. FWS-2-75. Division of Forestry \& Wildlife Resources. Virginia Polytechnic Institute and State University 1975 ; p143.

[38] Burkhart HE, Parker RC, Oderwald RG. Yields for natural stands of loblolly pine. Pub. FWS -2-72. Division of Forestry and Wildlife Resources. Virginia Polytechnic Institute and State University; 1972; p 63.

[39] Smalley GW, Bailey RL. Yield tables and stand structure for shortleaf pine plantations in Tennessee, Alabama, and Georgia highlands. RP-SO-97. USDA Forest Service, Southern Forest Experiment Station, New Orleans, LA 1974; p 57.

[40] Burkhart HE, Parker RC, Strub M R, Oderwald RG. Yields for old-field loblolly pine plantations. Pub. FWS-3-72. Division of forestry and wildlife resources. Virginia Polytechnic Institute and State University; 1972; p 51.

[41] U.S. Department of Agriculture. Volume, yield, and stand tables for second-growth southern pines. Miscellaneous Publications No. 50. USDA Forest Service, Washington, DC (revised 1929 edition) 1976; p 202.

[42] Lohrey RE, Bailey RL. Yield tables and stand structure for unthinned longleaf pine plantations in Louisiana and Texas. RPSO-133. USDA Forest Service, Southern Forest Experiment Station, New Orleans, LA 1977; p 53.

[43] Stiff CT. Modeling the growth dynamics of natural mixed-species Appalachian hardwood stands. Ph.D. Thesis. Virginia Polytechnic Institute and State University, Blacksburg, VA 1979; p209.

[44] Gardner WE, Marsh P, Kellison RC, Frederick DJ. Yields of natural hardwood stands in the southeastern United States. Hardwood Research Cooperative Series No. 1. School of Forest Resources, North Carolina State University, Raleigh, NC 1982; p 64.

[45] Voorhis N. Growth and yield predictions for upland oaks using programmable calculators. U.S. Department of Agriculture, Forest Service; 1983; p 40.

[46] Knoebel BR, Burkhart HE, Beck DE. A growth and yield model for thinned stands of yellow-poplar. Forest Science, Monograph 27; $1986 ;$ p 64. 
[47] Bowling EH, Burkhart HE, Burk TE, Beck DE. A stand-level multispecies growth model for Appalachian hardwoods. Can J For Res 1989; 19: 405-12.

[48] Carmean WH, Hahn JT, Jacobs RD. Site index curves for forest tree species in the Eastern United States. GTR-NC-128. USDA Forest Service, North Central Forest Experiment Station, St. Paul, MN 1989; p 142.

[49] Pienaar LV, Harrison WM, Rheney JW. Volume, weight and yield tables for slash pine plantations in the Southeastern Coastal Plain. Research Paper No. 78. Georgia Forestry Commission, Research Division; 1990; 47.

[50] Pienaar LV, Shiver BD, Rheney JW. Yield prediction for mechanically site-prepared slash pine plantations in the Southeastern Coastal Plain. PMRC Tech. Rep. 1996-3. Plantation Management Research Cooperative, Daniel B. Warnell School of Forest Resources, University of Georgia. Athens, GA 1996; p 57.

[51] Harrison, M. W., and B. E. Borders. Yield prediction and growth projection for site-prepared loblolly pine plantations in the Carolinas, Georgia, Alabama and Florida. PMRC Tech Rep 19961. Plantation Management Research Cooperative, Daniel B. Warnell School of Forest Resources, University of Georgia, Athens, GA 1996; P 64.

[52] Martin SW, Brister GH. A growth and yield model incorporating hardwood competition for natural loblolly pine stands in the Georgia Piedmont. South. J Appl For1999; 16(3): 179-85.
[53] Abt, RC, Cubbage FW, Pacheco G. Southern forest resource assessment using the subregional timber supply (SRTS) model. For Prod J 2000; 50(4): 25-33

[54] Zasada M, Cieszewski CJ, Lowe RC, Reimer D. Impact of adjacency and green up constraints on regional wood supply. In Proceedings of the Second International Conference on Forest Measurements and Quantitative Methods and Management \& The 2004 Southern Mensurationists Meeting. 15-18 June 2004, Hot Springs, AR, USA 2006; pp. 199-203.

[55] Lowe RE, Cieszewski CJ, Liu S, et al. Assessment of stream management zones and road beautifying buffers in Georgia based on remote sensing and various ground inventory data. South. J Appl For 2009; 33(2): 91-100.

[56] Zasada M, Cieszewski CJ, Lowe RC. Impact of stream management zones and road beautifying buffers on long-term fiber supply in Georgia. In: McRoberts RE, Reams GA, Van Deusen PC, McWilliams WH. Eds.Proceedings of the Fifth Annual Forest Inventory and Analysis Symposium. November 18-20, 2003, New Orleans, LA. GTR-WO-69. USDA Forest Service, Washington, DC 2005; 222.

[57] Liu S, Cieszewski CJ, Lowe R. Using outputs of the FIA Mapmaker to estimate sustainable harvests and intensively managed pine plantations. North Carolina State University, Forestry and Environmental Outreach Program, Proc. 2005 Southern Mensurationists Conf 2006.

(C) Cieszewski et al.; Licensee Bentham Open.

This is an open access article licensed under the terms of the Creative Commons Attribution Non-Commercial License (http://creativecommons.org/licenses/by$\mathrm{nc} / 3.0 /$ ) which permits unrestricted, non-commercial use, distribution and reproduction in any medium, provided the work is properly cited. 